\title{
UN RETRATO DESCONOCIDO DE ISABEL LA CATÓLICA*
}

\author{
PEDRO FLOR \\ Universidade Aberta de Lisboa \\ Instituto de Historia da Arte, Universidade Nova de Lisboa
}

Las reservas de la National Gallery de Londres albergan una pintura identificada como María Magdalena atribuida a un maestro desconocido de posible origen franco-flamenco. La identificación iconográfica del personaje se basa en el pequeño frasco que sujeta. Sin embargo, un análisis más detallado de la obra nos permite plantear la hipótesis de que se trate antes de un retrato de Isabel la Católica, no sólo por comparación con otros ejemplares iconográficos de la Reina, sino también por las joyas que ostenta. Partiendo de la comparación estilística con obras coevas resulta problemático determinar con precisión el autor de la pintura, pero es posible que se trate de Michel Sittow o alguien de su círculo de influencia, cuya actividad se conoce precisamente a finales del siglo XV y principios del XVI al servicio de la corona española.

Palabras clave: Renacimiento; Retrato; Isabel la Católica; Michael Sittow.

\section{AN UNKNOWN PORTRAIT OF ISABELLA THE CATHOLIC QUEEN}

The reserves of the National Gallery, London, house a painting identified as Mary Magdalene, by an unknown master most likely of Franco-Flemish origin. The iconographical identification of the subject derives from the small jar that she holds. A more thorough study of the piece, however, leads us to raise the hypothesis that it is actually a portrait of Isabella the Catholic, based on comparisons with other representations of this queen, as well as on the jewellery she wears. In spite of the stylistic comparisons made with contemporary works, it is difficult to establish the artist with precision. Nevertheless, we propose Michel Sittow -or someone from his artistic circle-whose activity at the service of the Spanish crown is documented precisely towards the end of the $15^{\text {th }}$ and beginning of the $16^{\text {th }}$ century.

Key words: Renaissance; Portrait; Isabella the Catholic; Michael Sittow.

La pintura María Magdalena que constituye el objeto de estudio de este artículo pertenece a la vasta colección de la National Gallery, encontrándose actualmente en las reservas de este importante museo londinense ${ }^{1}$. El intento de identificación del personaje representado y la posible

* Mi agradecimiento muy especial a la traductora del artículo la D ${ }^{a}$ Begoña Farré del Instituto de Historia da Arte - Faculdade de Ciências Sociais e Humanas da Universidade Nova de Lisboa, así como a D. Manuel Reyes Ruiz, Capellán Mayor de la Capilla Real de Granada, al Dr. Lázaro Gila Medina, al fotógrafo Carlos Madero y a nuestro colega David Martín López.

${ }^{1}$ Según los registros del museo: autor desconocido, Maria Madalena, h. 1520, $\mathrm{n}^{\circ}$ inv. NG 2615, óleo sobre madera, $41.3 \times 32.4 \mathrm{~cm}$. Agradecemos a Lorne Campbell, conservador y reputado investigador de la National Gallery, las facilidades proporcionadas en el acceso a las reservas museológicas y en la obtención de registros fotográficos y datos históricos acerca de esta pintura. Véase la imagen 1. 
reconstrucción del historial que envuelve la pintura constituyen los objetivos principales de este trabajo, en el que se procurará problematizar asimismo la cuestión de la autoría, ya abordada anteriormente por otros estudiosos ${ }^{2}$.

No se conoce de forma detallada el periplo histórico de esta pieza de la National Gallery, por lo que la labor de reconstrucción de su proveniencia está irremediablemente condenada al fracaso, habida cuenta del grado de complejidad de este tipo de investigación. La referencia más antigua que se ha conseguido hasta hoy nos asegura que la pintura pertenecía a la colección de Hollingworth Magniac (1786-1867), un influyente comerciante inglés conocedor del arte antiguo, en la que aparece inventariada, en 1862, en su residencia de Colworth. Treinta años más tarde fue vendida en subasta por su hijo y adquirida por los Durlacher, negociantes de arte, con el propósito de integrarla en la colección de Wickham Flower en Guildford. A principios del siglo XX (1904), la pintura sería vendida una vez más, esta vez a George Salting (1835-1909) quien poco después la prestó al Burlington Fine Arts Club con ocasión de una exposición dedicada a la retratística inglesa. El valioso legado de Salting a la National Gallery en 1910 incluía el cuadro en cuestión. Data de esa donación su permanencia definitiva en el museo $^{3}$.

La inscripción manuscrita en una etiqueta que aparece en el reverso de la pintura, fechable en el siglo XIX, pretende identificar el personaje como María Tudor (1496-1533) ${ }^{4}$. Sin embargo, un simple cotejo entre la iconografía de este personaje y nuestro cuadro invalida tal identificación, lo que nos lleva a pensar que la etiqueta representaría un ejercicio prematuro de reconocimiento de la imagen ${ }^{5}$.

Por su parte, Louis Dimier creyó ver en el cuadro la representación de Leonor de Austria (14981558), hermana de Carlos V, Reina de Portugal y Francia. Esta opinión fue rechazada más tarde por Roblot-Delandre con argumentos convincentes y por comparación iconográfica con retratos contemporáneos ejecutados por Jan Gossaert, de los que se conocen varias versiones ${ }^{6}$. Por su lado, Sánchez Cantón vio en la pintura de Londres la representación de otra hermana de Carlos V, concretamente Catalina de Austria (1507-1578), Reina de Portugal desde 1525, considerando incluso la joya ostentada por la figura como obra de un orfebre portugués, y la fisionomía de María Magdalena parecida a la del cuadro existente en el Museo del Prado que muestra a la reina como Santa Catalina ${ }^{7}$. Esta conjetura sería posteriormente contestada por Martin Davies, en el trabajo citado, quien defendía la hipótesis de que fuera una imagen de María Magdalena, sin descartar, no obstante, la posibilidad de que se tratase de un retrato, sospecha que perdura hasta hoy en la National Gallery. Nos proponemos, por consiguiente, arrojar nuevas interpretaciones sobre la pintura y su significado a partir de nuestra propia investigación.

De formato rectangular y remate semicircular, el cuadro de Londres presenta una figura femenina de rostro cándido, marcado por unos ojos claros, de un tono azul verdoso. El cabello dorado, probablemente recogido en una trenza, aparece coronado por una joya de oro, parecida a una dia-

\footnotetext{
${ }^{2}$ Davies, 1987:150-151. BaKer y Henry, 2001: 494.

3 Datos recogidos en DavIES, 1987: 151-152.

${ }^{4}$ María Tudor (1496-1533), hermana menor de Enrique VIII (1491-1547), reina de Francia entre 1514 y 1515 por su matrimonio con Luis XII (1462-1515) y, por último, Duquesa de Suffolk por su matrimonio con el primer Duque Charles Brandon (h. 1484-1545).

${ }^{5}$ Véase el dibujo de María Tudor como reina de Francia conservado en el Ashmolean Museum (Oxford) y la pintura de Woburn Abbey, en Bedfordshire, en la que aparece acompañada de su marido el Duque de Suffolk.

${ }^{6}$ Dimier, 1910: 69-70 y Roblot-Delondre, 1913: 157-158. Acerca de la retratística de Leonor de Austria, véase el más reciente catálogo de la exposición dedicada al pintor Jan Gossaert en 2010.

${ }^{7}$ Según Davies, la opinión de Sánchez Cantón se expresa en una carta conservada en el archivo de la National Gallery. Acerca de la iconografía de Catalina de Austria, véase por ejemplo Jordan, 1994: 157-159; Woodall, 2007; Marías, 2008 y FLOR, 2011: 314-317.
} 


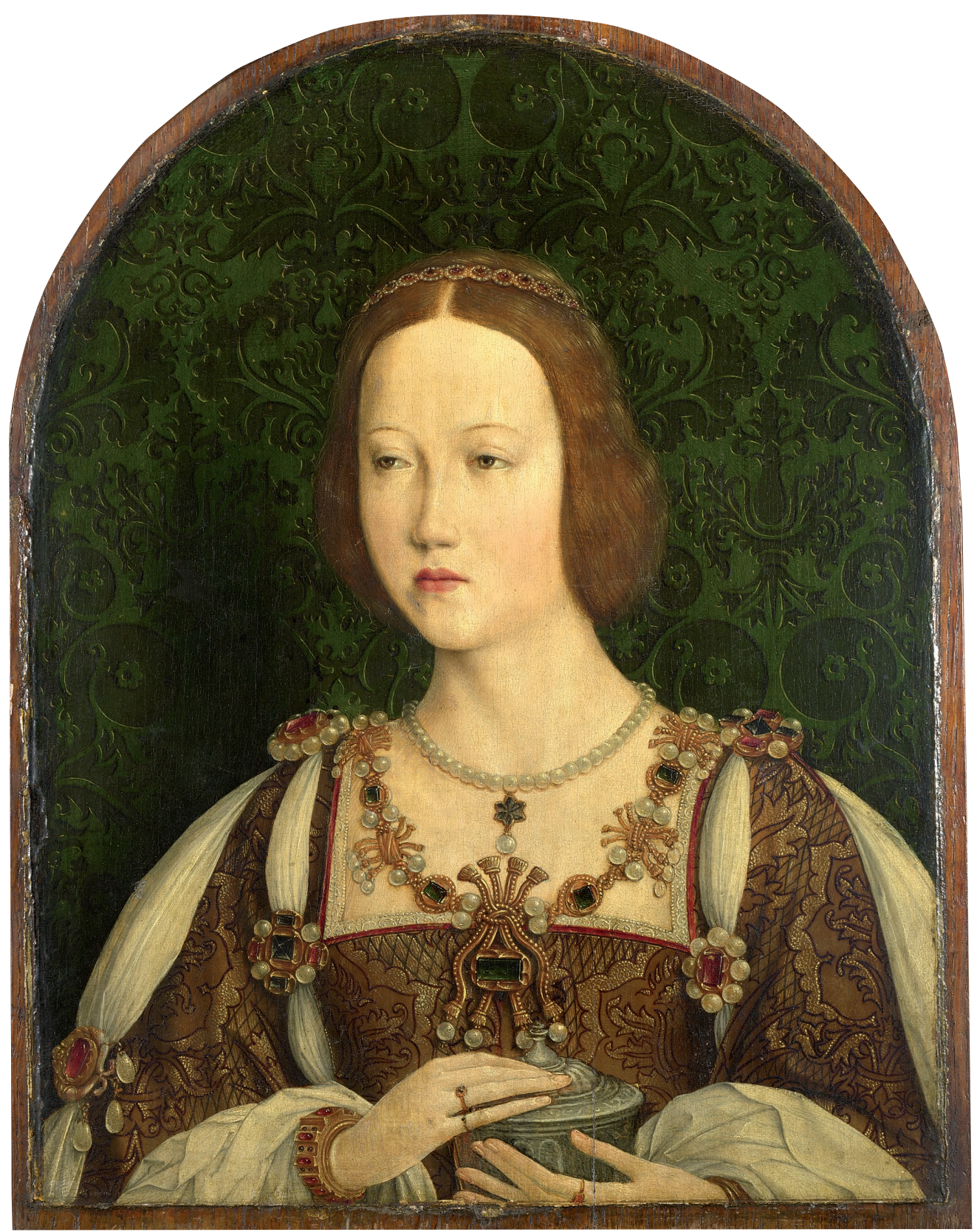

Fig. 1. Anónimo flamenco c. 1520. María Magdalena (?) (C) The National Gallery, London.

dema, con perlas y rubíes engastados. El personaje ostenta además un collar de perlas que termina en un colgante de zafiros, en forma de estrella, del que cuelga a su vez una perla de mayores dimensiones. Sobre los hombros y el pecho reposa un opulento collar de oro con esmeraldas y varios haces dorados con perlas. El minucioso trabajo de orfebrería exhibido en este collar atestigua su 
riqueza y singularidad. Los dedos, a su vez, muestran pequeños anillos de oro y rubíes. El vestido, ajustado y ejecutado con un brocado ricamente trabajado, presenta mangas abullonadas, sujetas con prendedores de oro, perlas, rubíes y zafiros. La figura lleva en las manos un pequeño recipiente de sobria decoración, semejante a un frasco con tapa. En el brazo derecho destaca un brazalete de oro denticulado, engastado una vez más con pequeños rubíes de forma ovalada y minúsculos zafiros circulares. El contorno del personaje, iluminado por el lado derecho, destaca sobre un fondo verde que procura imitar un drap d'honneur ${ }^{8}$.

Un análisis más detallado del cuadro suscita interrogantes demasiado importantes para que sean ignorados, sobre todo en lo que a la identificación iconográfica del personaje se refiere. Como ya se ha indicado, la existencia del frasco en primer plano llevó a Martin Davies a proponer que se tratase de una representación de María Magdalena, toda vez que dicho objeto alude a la unción de Cristo y constituye uno de los atributos más comunes de la iconografía de la santa ${ }^{9}$. Aunque el personaje ostenta un vestido lujoso y joyas riquísimas, aparato poco habitual en la caracterización de María Magdalena, estamos de acuerdo con los autores citados cuando sugieren la posibilidad de que se trate de una representación alegórica, tan al gusto del Renacimiento ${ }^{10}$. Dicho de otro modo, nos encontraríamos ante un retrato alegórico en el que la figura pierde su identidad real para asumir otra, adquiriendo al mismo tiempo sus virtudes y cualidades.

Observando atentamente el frasco percibimos que en su lugar hubo antes un libro (¿quizá un Libro de Horas?), aspecto que tanto puede denotar un pentimento durante la ejecución de la pintura como resultar de una modificación posterior. Sólo la realización conjunta de fotografías de espectro invisible y análisis de laboratorio permitirá en un futuro confirmar una de las hipótesis señaladas, aunque nos inclinemos, como Davies, por la de una rectificación coetánea a la realización de la pintura ${ }^{11}$.

Otro de los elementos iconográficos que sin duda merece atención es el majestuoso collar que puede contribuir a identificar a la retratada gracias a los peculiares haces entrelazados de pequeños cordones de oro, rematados por perlas, con uno mayor en el centro del que sobresale una enorme esmeralda ${ }^{12}$. Afortunadamente, durante la exhaustiva labor de investigación realizada, identificamos dos medallas con efigies muy parecidas a la del cuadro de Londres y nunca antes asociadas al mismo: una se conserva en la colección Jean Jadot (Bruselas) y la otra en el Archivo Histórico Nacional de Madrid. Ambas retratan, con leves diferencias, a la Reina Isabel la Católica (1451-1504) con un collar análogo al de la pintura ${ }^{13}$. La identidad del personaje retratado en las medallas viene confirmada tanto por la inscripción que las rodea como por los trazos fisionómicos ${ }^{14}$. Estas observaciones nos inducen a descartar la hipótesis de que se trate de una imagen religiosa que hubiera adoptado ciertos rasgos habsbúrgicos por imposición del comitente.

${ }^{8}$ El análisis del vestuario y las joyas ostentadas por la figura se basa en la bibliografía de Bernis, 1978-79. GrAz, 1999. Philips, 2008.

9 Véase por ejemplo Réau, 1999: 293-306.

10 Acerca de este concepto, léase por ejemplo Marín CruZado, 1999: 113-126. Falomir, 2004: 68-83. Redondo CANTERA, 2008: 3. FLOR, 2011: 93-95.

${ }^{11}$ Acerca de este tipo de examen fotográfico y de laboratorio, véase por ejemplo GarRIDo, 1990: 215-243. VerougsTRAETE y VAN SCHOUte, 1998: 101-115. Bomford (ed.), 2003.

12 BaKer y Henri, 2001: 494.

${ }^{13}$ Véanse las imágenes 2 y 3. Reproducciones recogidas en Vos, 1994: 47 y Río DE LA Hoz, 2001: 178 respectivamente.

${ }^{14}$ La inscripción de las medallas es idéntica: DIVA + HELISABET + HISPANIARVM + REGINA + SVPREMA + FOEMINARVM + CORONA. Obsérvese que la inscripción de la medalla del AHN se encuentra más desgastada que la del ejemplar de Bruselas, aunque por el tamaño y espaciado de los caracteres se perciba que se trata del mismo contenido escrito. 


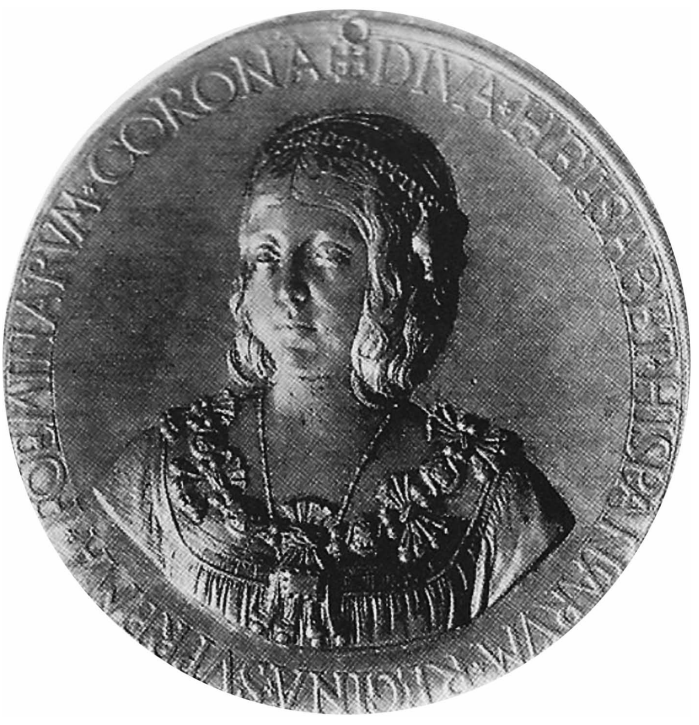

Fig. 2. Medalla con retrato de Isabel la Católica, Bruxelas, Col. Jean Jadot (imagen reproducida en Vos, Dirk, Hans Memling. The Complete Works).

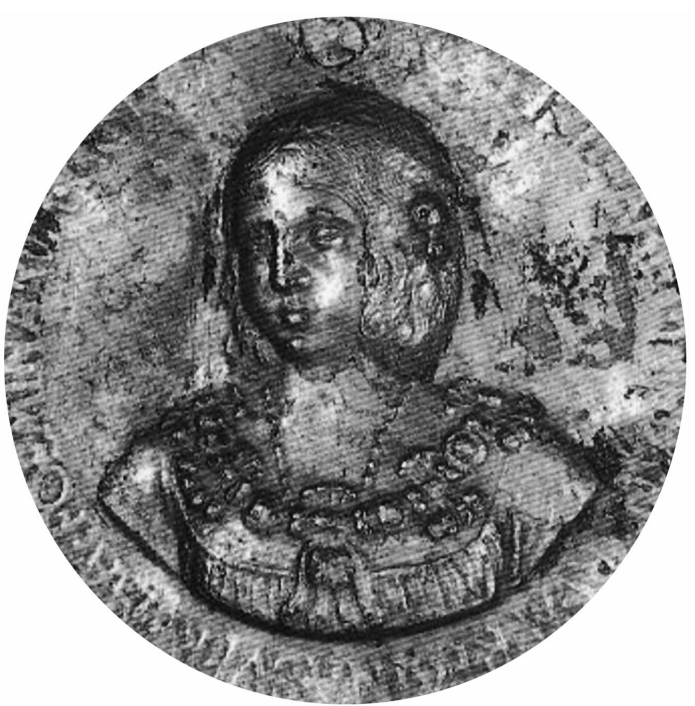

Fig. 3 Medalla con retrato de Isabel la Católica, Madrid, Archivo Histórico Nacional (imagen reproducida en Río de la Hoz, Isabel del, El Escultor Felipe Bigarny (h. 1470-1542).

Pocas diferencias separan la pintura de Londres de las dos medallas en cuestión: al margen de no estar representados en las medallas el colgante sobre el escote y los miembros superiores con sus respectivos aderezos (frasco y brazalete), y de diferencias de vestuario, se observa en ambas la existencia de una joya sujeta al cabello y, sólo en el ejemplar de Bruselas, una diadema con una inscripción en caracteres góticos ${ }^{15}$. Por lo contrario, cabe destacar la extraordinaria semejanza entre las obras en cuanto a la fisionomía, cándida y expresiva, de las tres imágenes, el posicionamiento de la retratada a tres cuartos y, por último, el collar con los haces de oro y la piedra preciosa destacada.

La identificación precisa de las facciones de la reina en los relieves de las medallas resulta difícil por el material en el que fueron ejecutadas, lo que no ocurre con la pintura. Efectivamente cabe destacar la extraordinaria coincidencia entre las descripciones que nos llegaron sobre la apariencia de la Reina Isabel y el aspecto general conferido a la figura pintada ${ }^{16}$. Las palabras, por ejemplo, de Hernando del Pulgar trazando el retrato físico de Isabel, que hasta mencionan la hibridez en el color de los ojos, parecen describir de hecho la figura del cuadro londinense: «Esta Reina era de mediana estatura, bien compuesta en su persona y en la proporción de sus miembros, muy blanca y rubia: los ojos entre verdes y azules, cara hermosa y alegre, el mirar gracioso y honesto, las facciones del rostro bien puestas» ${ }^{17}$. Tanto en las medallas como en la pintura la Reina aparenta una permanente juventud, característica que llegó a impresionar a sus contemporáneos,

15 Arbeteta Mira, 2005: 49-66 y Eichberger, 2010: 2372. A inscrição diz-nos o seguinte: FIDEI TUTAMEN.

16 Ladero Quesada, 2005: 46-48.

${ }_{17}$ Crónica de los Señores Reyes Católicos..., II parte, cap. IV, p. 37. Texto destacado en negrita por el autor del artículo. Léase a este respecto el trabajo de BERMEJo MARTínEZ, 1991: 49-56. 
como es el caso de Jerónimo Münzer que, en su Viaje de 1494, subraya esta marca distintiva del

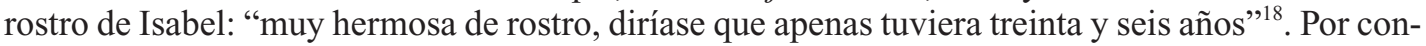
siguiente, estos dos testimonios literarios se plasman en el cuadro de Londres, que retrata una bella joven alba y rubia, de ojos de color híbrido, en la atemporalidad de cuyo rostro se hacen eco las palabras de Münzer.

Teniendo en cuenta la práctica retratística de la época y la utilización habitual de pinturas, o de la pose representada en las mismas, como modelos para otras artes subsidiarias como el xilograbado, la numismática y la medallística, aceptemos por el momento la hipótesis de que nos encontramos ante la obra matriz (o su copia) que habría servido de prototipo iconográfico para las dos medallas analizadas ${ }^{19}$. Concretamente, el modelo de la pintura de Londres habría constituido la base fundamental de inspiración de los retratos post mortem de Isabel la Católica figurados en las medallas, ejecutadas ya en el siglo XVI (1514) según demostraron Luc Smolderen y Dirk de $\operatorname{Vos}^{20}$. De entre la iconografía isabelina conocida en la época, el autor o autores de las medallas se sirvieron como fuente común de una pintura que debería ser muy apreciada en la época, hasta el punto de ser reproducida en otros materiales.

Se sabe por la documentación de archivo, publicada hace tiempo, que existió un retrato de Isabel la Católica en el que aparecía, precisamente, con 30 años de edad. Efectivamente, los inventarios realizados en 1516 y 1523 de la colección de retratos de Margarita de Austria (1480-1530), regente de los Países Bajos a partir de 1507 por designación del Emperador Maximiliano I, registran un elevado número de ejemplares de la autoría de pintores de la categoría de Rogier Van der Weyden, Joos Van Cleve, Bernard van Orley y Jan Gossaert ${ }^{21}$. Estas imágenes que adornaron en su momento los diversos espacios del Palacio de Malinas, en particular la biblioteca y la primera cámara, constituían una verdadera galería de retratos de demostrada coherencia y fuerte significado simbólico para la afirmación de la dinastía de los Habsburgo ${ }^{22}$.

El inventario de 1516 da fe precisamente de la existencia de un retrato de Isabel la Católica cuyo autor aparece claramente identificado: "ung petit tableaul du chief de la royenne en son eage de XXX ans, fait par maistre Michel”. Años más tarde, como ya demostró Sánchez Cantón con convincentes argumentos, el listado de 1523 registra el mismo cuadro, describiéndolo ahora en detalle aunque sin mencionar la edad de la retratada: "ung aultre tableau de la portraiture de la feue royenne d'Espaigne, Done Ysabel, que dieu pardoint, a ung colier d'emeraudes parles et aultres pierres precieuses et une bague du coustel de son chief, a une parle" ${ }^{23}$. La falta de una indicación expresa de la edad podría llevar a la conclusión de que se tratase de cuadros diferentes. No obstante, los inventarios registran un único retrato de Isabel la Católica y se sabe que entre 1516 y 1523 no se encargaron otras pinturas de la reina española.

En suma, existió un retrato de Isabel la Católica documentado en la colección de Margarita de Austria, realizado por el pintor estonio Michel Sittow (h. 1468-1525/26), en el que la reina aparecía con treinta años y llevaba un collar de esmeraldas, perlas y otras piedras preciosas ${ }^{24}$. Que el cuadro de Londres sea o no el ejemplar (o una copia del original) que estuvo en la colección de Malinas, no es algo que podamos afirmar con seguridad. Pero cabe destacar en cualquier caso la extraordinaria coincidencia, nunca antes mencionada, entre los registros existentes en los dos inventarios, la descripción iconográfica que contienen, la pieza londinense y las dos medallas.

\footnotetext{
${ }^{18}$ LAdero Quesada, 2005: 47.

19 Acerca de la medallística del Renacimiento, véase CoRRAdinI, 1998: 22-39 y CAMPBELL, 2008: 32-45.

${ }^{20}$ SMOLDEREN, 1968: 81-86 y Vos, 1994: 46.

${ }^{21}$ Le Glay, 1839 y Michelant, 1871. Véase recientemente Eichberger, 2010.

${ }^{22}$ Eichberger y Beaven, 1995 y Eichberger, 2010: 2337-2349.

23 SÁnchez Cantón, 1950: 153.

24 Trizna, 1976 y WolfF, 2010.
} 
A partir de los datos cronológicos relativos a la vida de Isabel la Católica y a la carrera conocida de Sittow (a quien la documentación también se refiere como Melchior Alemán), constatamos que la pintura de Londres quizá podría ser el ejemplar que perteneció a la colección de Margarita de Austria. No obstante, la fecha de ejecución de dicha pintura no se situaría en los años 80 del siglo $\mathrm{XV}$, como la edad de la retratada podría hacer suponer, sino unos años más tarde, quizá coincidiendo con la estancia de Sittow en España precisamente al servicio de los Reyes Católicos, desde 1492 hasta 1504, período en el que percibió elevadas cantidades de dinero. Lamentablemente, no encontramos una explicación definitiva para la diferencia entre la inscripción relativa al cuadro (30 años de edad, que correspondería a una fecha de ejecución en los años 80 del siglo XV) y la actividad documentada y conocida de Sittow en la Península (que apuntaría a un periodo de ejecución en la década de 90).

Además del flamenco Juan de Flandes (al servicio de la Corona desde 1496, con una remuneración anual inicial de 20.000 maravedís que pasó después a 30.000 maravedís), y del francés Felipe Morras (que desde 1497 ganaba 15.000 maravedís anuales por trabajos de pintura y miniatura), Michel Sittow (con un estipendio anual de 50.000 maravedís) fue quien más gozó de la protección mecenática de Isabel, haciéndose cargo de varios retratos de pequeño formato en los que representaría tanto a los reales descendentes como a los propios Reyes Católicos, según la información recabada una vez más en los inventarios de Margarita de Austria ${ }^{25}$.

A nuestro entender, el límite cronológico para la ejecución de la pintura deberá situarse entre 1492, año de inicio de la actividad documentada de Sittow en la Península Ibérica, y 1514, fecha de acuñación de las medallas de Bruselas y Madrid que se limitan a repetir el modelo iconográfico entretanto ya instituido y aceptado por la reina. Admitimos la posibilidad de que fuera Diego Flores (¿alrededor de 1505, después de fallecer Isabel la Católica?) el agente responsable de la adquisición de la pintura con el propósito de enriquecer la colección privada de la Regente de los Países Bajos ${ }^{26}$.

Desde el punto de vista plástico, la pintura de Londres se aproxima en cierto modo a la manera de Sittow que acusa la lección de Hans Memling, representando el modelo más común del final del Cuatrocientos que se prolongaría durante un siglo más: retratos de medio cuerpo con cabeza a tres cuartos y fondo neutro en contraste con el brillo del rostro ${ }^{27}$. Aun así, una cierta inexpresividad facial, el dibujo demasiado alargado de las manos y el brocado de color como escenario de representación son elementos que parecen contradecir la afirmación anterior. Por este motivo, ponderamos seriamente el considerar la pintura londinense como una copia de un original de Sittow, perdido o no localizado, lo que legitimaría las mencionadas diferencias plásticas que se pueden constatar mediante comparación con la obra documentada del pintor estonio. A propósito de la autoría y a título de curiosidad, existe en el archivo de la National Gallery una nota escrita de Luís Reis-Santos (1898-1967), historiador de arte especializado en pintura portuguesa, que proponía para la obra en cuestión la mano del pintor flamenco Frei Carlos (a. 1517-1539), igualmente deudor de la estética brujense de Hans Memling ${ }^{28}$. Con todo, la falta de elementos técnicos que permitan caracterizar el proceso creativo de la pintura de Londres en estrecha comparación con lo que hoy sabemos acerca de la manera de Frei Carlos, nos impide profundizar en dicha pista de investigación. De ser verificada, no obstante, esta llenaría la laguna biográfica que existe en la carrera de este pintor flamenco que, de este modo, antes de su llegada a Portugal habría pasado por España y ejecutado esta tabla por encargo regio ${ }^{29}$.

25 Domínguez Casas, 2008: 140.

${ }^{26}$ ISHIKAWA, 2003: 106.

27 Vos, 1994: 365-370 y BORCHERT, 2005.

${ }^{28}$ Agradecemos la amabilidad de Lorne Campbell por el acceso facilitado a la documentación en archivo acerca de la pintura objeto de estudio.

${ }^{29}$ A falta de un análisis material de la pintura, no obstante, nos es imposible dar seguimiento a esta interesante hipótesis de trabajo. Acerca de Frei Carlos, véase Couto, 1955; y Carvalho, 2010: 156-173. 
De no ser por la comparación iconográfica y estilística con las medallas de Bruselas y Madrid, que nos parece corroborar la identificación de Isabel la Católica, podríamos pensar que se trata de un cuadro del primer cuarto del siglo XVI por cotejo con la retratística de la época (modelo de vestido, joyas sobre el pelo y caracterización del estilo pictórico). No obstante, estos elementos más comunes de la pintura de principios del Quinientos se justificarían aceptando que la obra de Londres constituyese una copia posterior (y actualizada) de una versión más antigua.

El profundo conocimiento que hoy se tiene del tesoro de la Reina nos permite comprender la importancia simbólica de las joyas de Estado que reunía, en una coyuntura de escenificación pública de la Monarquía a través de un riguroso ceremonial de corte. La apuesta deliberada por la propaganda política con el propósito evidente de afirmar la unión entre Castilla y Aragón resultó en la magnificencia con que el poder se tradujo precisamente en variadísimas obra de orfebrería patrocinadas por la Monarquía ${ }^{30}$. En este conjunto de collares ricos, joyeles, bronchas y coronas, se sabe que Isabel la Católica poseía un collar de las flechas o frechas que pesaba cinco marcos y dos onzas, todo él hecho de oro, perlas y piedras preciosas, y de tan elevado valor que incluso llegó a servir como garantía para préstamos a la Corona ${ }^{31}$. La abundancia de mano de obra capaz de ejecutar piezas de esta naturaleza, de la que son excelentes ejemplos los orfebres Jaume Almerique o Aimerich (también guardajoyas de la Reina en 1481), Rodrigo Alonso y Pedro Vigil, facilitaba el encargo de valiosos artículos de oro y plata, promoviendo un gusto por los mismos que se generalizó a la Corte española ${ }^{32}$.

De naturaleza todavía medievalizante, aunque su aplicación anuncie ya con frecuencia un cariz renacentista, el uso iconográfico de las flechas en estrecha asociación metafórica con Isabel la Católica fue glosado en su momento por el humanista salmantino Lucio Flaminio (a.1486-1509) ${ }^{33}$. Efectivamente, el uso de este emblema heráldico se asocia a la simbólica intrínseca del bien sobre el mal, por lo que tradujo, en cierto modo, las grandes empresas españolas llevadas a cabo por los Reyes Católicos: la victoria militar sobre los musulmanes, la apertura de nuevas rutas atlánticas, la expulsión de los judíos del Reino y la unión política y cultural promovida por la constitución de un Imperio ultramarino. En contraste con la dispersión de las flechas al ser lanzadas por un arco, la reunión de las mismas en un haz simboliza el sentido de unión, sujeción y fuerza. Este símbolo que Isabel la Católica quizá quiso emplear como homenaje a su marido y que también quiso imprimir a su gobierno y a la Corona recientemente unificada, así como la imagen que deseó fijar entre sus súbditos, aparecen de este modo sintetizados en una pieza de orfebrería de elevado valor simbólico y didáctico ${ }^{34}$.

El número de flechas representadas varió, con todo, de un emblema para otro. Ortega Lamadrid registra oscilaciones entre cinco y catorce unidades, considerando el siete como el número más habitual ${ }^{35}$. En el collar, los haces representados no contienen más que cuatro, un número reducido quizá por la naturaleza del material en el que fueron labrados.

En la investigación realizada identificamos otro collar muy parecido al de Londres que aparece cincelado en la estatua yacente de Juana la Loca (1479-1555), obra de Bartolomé Ordóñez (h. 1480$1520)^{36}$ (fig. 4). Arbeteta Mira ya subrayó la calidad del trabajo escultórico evidente en la pieza de

30 Yarza Luaces, 1993; Ishikawa, 2003: 103-154 y Arbeteta Mira, 2004: 169-176.

31 Arbeteta Mira, 2004: 172-179 y Muller, 1972.

32 Arbeteta Mira, 2004: 172-173.

33 Ortega Lamadrid, 1951: 112-113.

34 Domínguez Casas, 2008: 125-127. La propia inscripción que consta en la diadema de la medalla de Bruselas, Fidei Tutamen, parece aludir también al poderío y a la importancia militar ostentada por su marido, Fernando de Aragón.

35 Ortega Lamadrid, 1951: 114-115.

36 Acerca de Bartolomé Ordóñez los sepulcros de la Capilla Real de Granada, véase por ejemplo LÉON CoLOMA, 1994: 69-95 y CARBonell i BuAdes, 2000. 


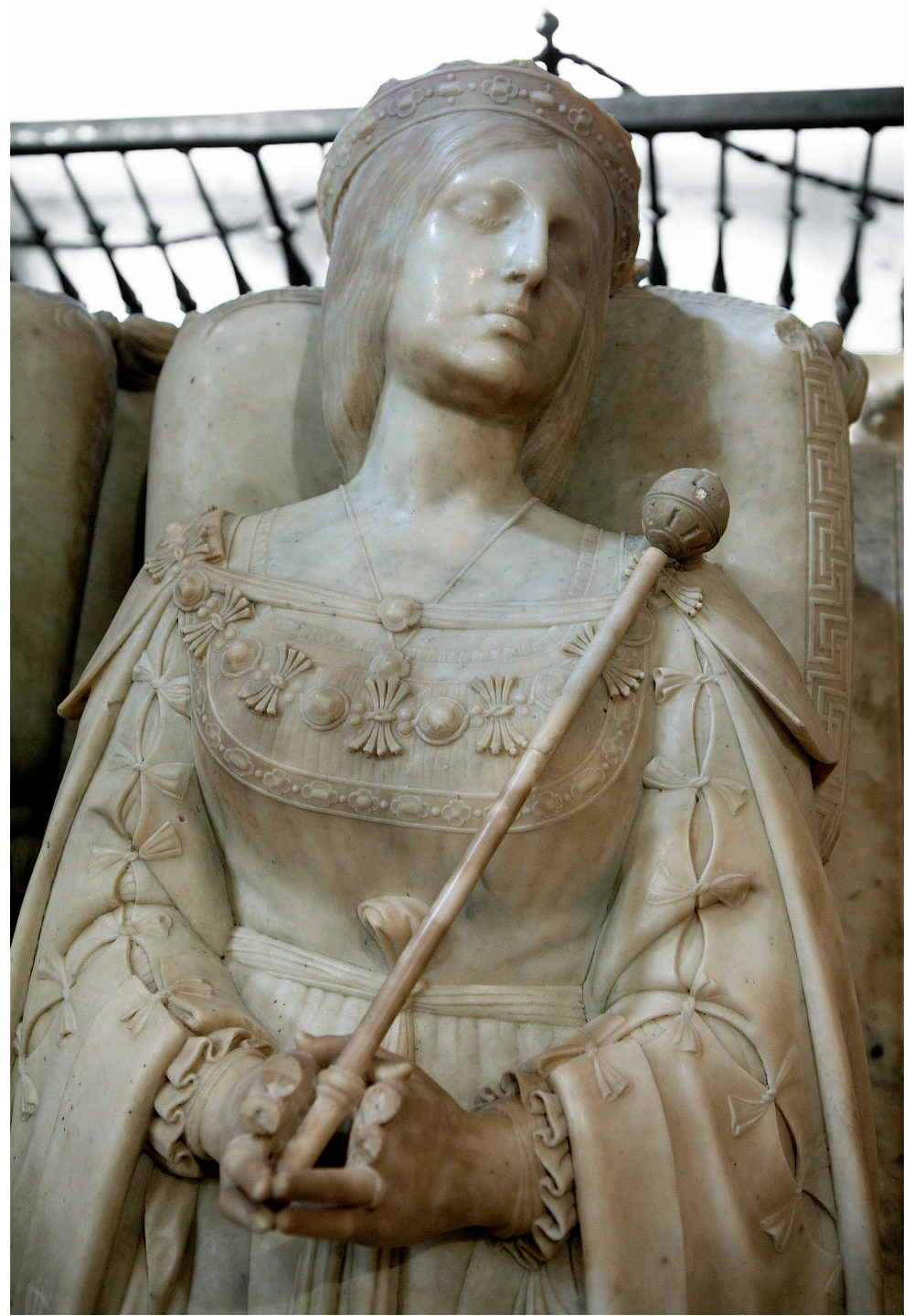

Fig. 4. Sepulcro de Juana I de Castilla (detalle). Catedral de Granada. (C) Carlos Madero.

orfebrería ostentada por la yacente, si bien detectó ciertas diferencias entre la obra esculpida y la descripción conocida del collar. Sugerimos la posibilidad de que la estatua presente una joya que antaño perteneciera a Isabel la Católica y que hubiera sido heredada por su hija ${ }^{37}$. De hecho, según la costumbre de la época, es posible que el collar estuviera en posesión de Isabel la Católica durante muchos años y que fuera legado todavía en vida, o posteriormente, a Juana. La singularidad de la pieza y el inestimable valor que poseía justificaría desde luego la decisión de hacerla figurar sobre la estatua yacente del mausoleo granadino. Lamentablemente el uso indiferenciado de las joyas, tantas veces adaptadas o profundamente modificadas, habría contribuido a su desaparición, no solo

${ }^{37}$ ZaLAmA, 2010: 848-849. 
por su extraordinario valor sino también por lo apetecible de los materiales, fácilmente aprovechados a lo largo de los siglos para nuevas joyas más al gusto de la época. En la lectura de los inventarios disponibles de Juana la Loca no fue posible identificar tal joya, a pesar del considerable número de piezas de joyería que la misma poseía ${ }^{38}$.

Que el collar se mantuviera algunos años en el tesoro de Juana la Loca se justifica por la utilización que ella misma hizo del haz de flechas como emblema personal ${ }^{39}$. El uso de esta joya posteriormente a la muerte de Isabel la Católica y su ostentación en una escultura de carácter funerario son indicadoras de la importancia simbólica de la pieza en la corte española. Asimismo, la boda de Juana la Loca y Felipe el Hermoso en 1496 habría generado la necesidad de un nuevo esfuerzo de reafirmación del poder español en el seno del vínculo dinástico de ambas coronas, fortalecido así en el contexto diplomático de la Europa de finales de siglo XV frente a la ascensión de los Valois en Francia.

Lamentablemente, a excepción de las medallas de la colección Jadot de Bruselas y del Archivo Histórico Nacional de Madrid, evidencia fidedigna de la iconografía isabelina confirmados por la inscripción, no encontramos otros testimonios visuales de Isabel la Católica con cerca de 30 años, ni tampoco con una joya semejante. Todo lo que hoy se conoce de su iconografía se remonta a épocas un poco posteriores: la representación integrada en el Milagro de la multiplicación de los panes y los peces (h. 1496-1504) de Juan de Flandes, en su momento en la colección de Isabel y hoy en el Palacio Real de Madrid, así como el retrato de hacia 1500, conservado en la misma institución (¿procedente de la Cartuja de Miraflores de Burgos?), de autoría todavía desconocida, constituyen buenos ejemplos de imágenes que nos muestran facciones más envejecidas y un modo de retratar bien diferente del que observamos en Londres ${ }^{40}$.

Antes de concluir nuestra lectura del cuadro ahora revelado para la historia de la iconografía de Isabel la Católica, cabe reflexionar sobre el posible significado iconológico de su figuración como María Magdalena. Para ello partiremos de la idea, por confirmar a través de análisis técnicos, que el frasco del primer plano corresponde a la intención original del artista, en lugar del libro que se vislumbra por entre los dedos.

Como ya indicamos, la representación alegórica es frecuente durante el Renacimiento y se emplea en la práctica retratística contemporánea ${ }^{41}$. Desde siempre se asociaron a Isabel la Católica los trazos característicos de la Virgen María, en particular la piedad, la pureza y la honestidad, traducidos en la conducta de vida espiritual (y también cultural) adoptada a lo largo de su reinado, así como en la imagen modélica que procuró transmitir a cuantos la rodeaban. Según Ladero Quesada, los autores que cantaron a Isabel la Católica, entre ellos Baldassare Castiglione en la obra El Cortesano, casi siempre hicieron hincapié en su condición femenina sin par y en su demostrada capacidad de gobierno, así como el temor de Dios, la cortesía y la liberalidad ante sus pares, la prudencia y la templanza en la toma de decisiones y, por último, el ejemplo de bondad que constituyó para todos ${ }^{42}$. Su ánimo, tan al gusto medieval, de reunir un fondo artístico variado, verdadero tesoro conseguido a lo largo de los años, refleja precisamente una actitud reverencial y devota, más que una postura de coleccionista consciente del valor intrínseco de los objetos, figura que se consagraría más tarde, con el Renacimiento ${ }^{43}$.

Dicho de otro modo, las características morales de la Reina reflejan los deberes ideológicos que marcaron su gobierno, lo que se traduce forzosamente en una representación iconográfica, a lo

\footnotetext{
38 ZaLAma, 2010: 837-873.

39 Domínguez Casas, 2008: 133.

40 Silva Maroto, 2004: 124-126.

${ }^{41}$ Véase por ejemplo Pommier, 1998: 62-103

${ }^{42}$ Ladero Quesada, 2005: 232-237.

43 Véase por ejemplo SÁnchez CANTón, 1950: Yarza LuACES, 1993: 100-102 e IshiKaWA, 2003: 104.
} 
divino', íntimamente ligada a su afirmación cada vez mayor como figura modélica que conseguiría satisfacer las necesidades políticas y culturales de la nueva España tras la conquista de Granada en 1492. Al mismo tiempo, la imagen de Isabel se convertía en un ejemplo para las mujeres de la sociedad contemporánea, estableciendo así las reglas de conducta de vida y moral para todos ${ }^{44}$.

En este contexto, parece plausible la probable estrategia visual adoptada por la monarca al hacerse retratar como María Magdalena perfumadora, en sintonía con las representaciones más comunes del arte de los siglos XV y XVI ${ }^{45}$. Este ejemplo de retratística alegórica no parece ser un caso único, pues la escultura Santa Catalina de Alejandría (h. 1504-1505), atribuida a Felipe Vigarny, se cree que representa a Isabel la Católica, dadas las grandes semejanzas fisionómicas y de indumentaria entre ambas ${ }^{46}$. Es probable, por lo tanto, que en otro contexto iconográfico la Reina quisiese encarnar a otros personajes igualmente importantes de la liturgia y el imaginario cristiano.

Veamos por ahora el caso de Isabel como María Magdalena. El imaginario medieval y el pensamiento cristiano ven a María Magdalena como penitente y símbolo de la contrición humana: un ejemplo a seguir por todas las que, mediante la penitencia se redimían a los ojos de Dios. Por consiguiente, en un ambiente en el que la sociedad de corte crecía de forma progresiva, al asumir el papel de Magdalena, Isabel la Católica querría ciertamente transmitir el ejemplo de un comportamiento moral de profunda devoción, en conjunción con el oficio divino, la celebración eucarística y la oración litúrgica, elementos fundamentales y estructurales de la vida cotidiana. El cultivo de una faceta de gran rigor y elevado fervor religioso, propia de la devotio moderna en boga en el Norte de Europa y en la Península Ibérica, habría fundamentado el comportamiento de Isabel que de este modo asumía el designio de mensajera de un misticismo emergente e innovador. Se trata de una espiritualidad contemplativa y de extrema dedicación a Dios, también admirada y pregonada por el confesor de la Reina, que sin duda influyó en ella, el poderoso Cardenal Cisneros (14361517). La nueva actitud de vivencia de un Cristianismo renovado marcó todo el reinado de Isabel. En dicho contexto, la pintura de Londres parece constituir un efectivo testimonio simbólico de propaganda ideológica.

El desarrollo de estudios en profundidad acerca del arte y las estrategias iconológicas del retrato tardomedieval y renacentista en la Península Ibérica ha permitido un mayor y más actualizado conocimiento de esta temática. Con el presente trabajo esperamos haber contribuido, de algún modo, a estimular nuevas investigaciones sobre estos asuntos, renovando al mismo tiempo la problemática en torno a la iconografía de Isabel la Católica que contará, a partir de ahora, con un nuevo ejemplar. La incertidumbre derivada de la figuración de María Magdalena, aun considerando creíble su representación desde una perspectiva simbólica, la determinación exacta de la autoría y las circunstancias que llevaron la pintura hasta la National Gallery en el siglo XX, continúan siendo interrogantes a los que no conseguimos dar una respuesta cabal pero que esperamos ver resueltos en breve por la comunidad científica.

\footnotetext{
${ }^{44}$ Gatland, 2010: 31-50.

${ }^{45}$ Ver Réau, 1997: 293-306. De hecho, la representación como María Magdalena será utilizada más tarde en la casa de Habsburgo, concretamente en el retrato de Isabel de Austria (1501-1526), hermana de Carlos V, como se puede observar en el cuadro conservado en el Museo Real de Bellas Artes de Bruselas, atribuible a Jan Gossaert, nº inv. 4341.

${ }^{46}$ Esta imagen 'a lo divino' perteneció en su momento al antiguo retablo de la capilla de la Universidad de Salamanca, encontrándose hoy en Valladolid, en el Museo Nacional Colegio de San Gregorio. Véase MARCos ViLLÁN, 2009: 76.
} 


\section{BIBLIOGRAFÍA}

Ainsworth, Maryan W., Foister, Susan, Alsteens, Stijn, Orenstein, Nadine, Campbell, Lorne, Man, Myth, and Sensual Pleasures: Jan Gossart's Renaissance: The Complete Works, cat. Exp., Yale University Press, 2010.

Arbeteta Mira, Letizia, «La corona rica y otras joyas de estado de la reina Isabel I», en Checa Cremades, Fernando (coord.), Isabel la Católica - La Magnificencia de un Reinado, cat. Exp., Sociedad Estatal de Conmemoraciones Culturales / Junta de Castilla y León, 2004, pp. 169-186.

Arbeteta Mira, Letizia, «Los brincos o pinjantes, una moda española en la Europa del siglo XVI», en Rivas Carmona, Jesús (coord.), Estudios de Platería - San Eloy, Universidad de Murcia, 2005, pp. 49-66.

Baker, Christopher y Henry, Tom, The National Gallery - Complete Illustrated Catalogue, National Gallery Publ., London, 3 ed., 2001.

Bernis, Carmen, Trajes y modas en la España de los Reyes Católicos, Instituto Diego Velázquez, Madrid, 1978-1979.

Bermejo Martínez, Elisa, «Retratos de Isabel la Católica», Reales Sitios, n 110, 1991, pp. 49-56.

Bomford, David (ed.), Art in the Making - Underdrawings in Renaissance Paintings, cat. Exp., National Gallery, London, 2003.

Borchert, Till-Holger (ed.), Memling's Portraits, cat. Exp., Thames \& Hudson, London, 2005.

Campbell, Lorne, Falomir, Miguel, Fletcher, Jennifer, Syson, Luke (ed.), Renaissance Faces - Van Eyck to Titan, cat. Exp., National Gallery, London, 2008.

Carbonell i Buades, Marià, «Bartolomé Ordóñez i el cor de la catedral de Barcelona», en Locus Amoenus, $\mathrm{n}^{\circ} 5,2000,117-147$.

Carrasco Manchado, Ana Isabel, «Isabel la Católica y las ceremonias de la monarquía», en e-Spania [Online], $\mathrm{n}^{\mathrm{o}} 1$, junio 2006, publicado online a 2 junio 2010, consultado el 11 octubre 2011. URL: http://e-spania.revues.org/308; DOI: 10.4000/e-spania.308.

Carvalho, José Alberto Seabra y Caetano, Joaquim Oliveira (coord.), Primitivos Portugueses (1450-1550) o século de Nuno Gonçalves, cat. Exp., Athena, Lisboa, 2010.

Corradini, Elena, Medallic portraits of the Este: effigies ad vivum expressae, en Mann, Nicholas y Syson, Luke (ed.), The Image of the Individual - Portraits in the Renaissance, The British Museum Press, London, 1998, pp. 22-39.

Couto, João, A oficina de Frei Carlos, Ed. Artis, Lisboa, 1955.

Davies, Martin, The Early Netherlandish School, National Gallery Publ., London, 4 ed., 1987.

Dimier, Louis, Portraits des Rois et Reines de France, Bureau de l'Action Française, Paris, 1910.

Domínguez Casas, Rafael, «The artistic patronage of Isabel the Catholic: Medieval or Modern?», en Weissberger, Barbara (ed.), Queen Isabel I of Castille - Power, Patronage and Persona, Tamesis, Woodbridge, 2008, pp. 123-148.

Eichberger, Dagmar, «Margarita de Austria y la documentación de su colección de Malinas», in Checa Cremades, Fernando (dir.), Los Inventarios de Carlos $V$ y la familia imperial, vol. III, Fernando Villaverde Ed., The Getty Foundation, 2010, pp. 2337-2349.

Eichberger, Dagmar y Beaven, Lisa, «Family Members and Political Allies: the Portrait Collection of Margaret of Austria», en Art Bulletin, vol. LXXVII, n 2, 1995, pp. 225-248.

Falomir, Miguel, «Los orígenes del retrato en España. De la falta de especialistas al gran taller», en Portús Pérez, Javier (ed.), El Retrato Español - del Greco a Picasso, cat. Exp., Museo del Prado, Madrid, 2004, pp. 68-83.

Flor, Pedro, A Arte do Retrato em Portugal nos séculos XV e XVI, Assírio \& Alvim, Lisboa, 2011.

Graz, Marie-Christine Autin, Jewels in Painting, Skira, Milano, 1999.

Gatland, Emma, «Saintly models: Isabel la Católica and the commissioning of a flos sanctorum», en Journal of Medieval Iberian Studies, vol. 2, n 1, 2010, pp. 31-50.

Ishikawa, Chiyo, «La llave de Palo: Isabel la Católica as patron of religious literature and painting», Boruchoff, David A. (ed.), Isabel la Católica, Queen of Castille: Critical Essays, MacMillan, New York, 2003, pp. 103-154.

Jordan, Annemarie, Retrato de Corte em Portugal: o legado de Anthonis Mor, Quetzal Ed., Lisboa, 1994.

Ladero Quesada, Miguel Ángel, «Isabel la Católica vista por sus contemporáneos», en Isabel la Católica y su tiempo, Ciclo de Conferencias en Conmemoración del V Centenario de la muerte de Isabel la Católica, Real Academia de la Historia, Fundación Ramón Areces, 2005, pp. 37-107. 
Le Glay, A. (ed.) Correspondance de l'Empereur Maximilien Ier et de Marguerite d'Autriche, sa fille, gouvernante des Pays-Bas de 1507 à 1509, publiée d'après les manuscrits originaux, Paris, 1839.

León Coloma, Miguel Ángel, «Los Mausoleos Reales y la Cripta», en Pita Andrade, José Manuel (coord.), El Libro de la Capilla Real, Granada 1994, pp. 69-95.

Marcos Villán, Miguel Ángel, «Santa Catalina de Alejandría», en Bolaños Atienza, Maria (dir.), Museo Nacional Colegio de San Gregorio - colección, Torán, 2009, pp. 76-77.

Marías, Fernando, «Revisando a Antonio Moro entre España y Portugal», en Redondo Cantera, María José y Serrão, Vítor (coord.), Actas do Simpósio Internacional: O Largo Tempo do Renascimento-Arte, Propaganda e Poder, Caleidoscópio, Lisboa, 2008, pp. 11-50.

Marín Cruzado, Olga, «El retrato real en composiciones religiosas de la pintura del siglo XVI», El arte en las Cortes de Carlos V y Felipe II, Novenas Jornadas de Arte, Consejo Superior de Investigaciones Científicas, 1999, pp. 113-126.

Michelant, H., «Inventaire des vaisselles, joyaux, tapisseries, peintures, manuscrits etc. de Marguerite d'Autriche, régente et gouvernante des Pays-Bas, dressé en son palais de Malines, le 9 juillet 1523», Académie Royale des Sciences des Lettres et des Beaux-Arts de Belgique, Bulletin de la Comission Royale d'Histoire, série 3, XII, 1871, pp. 33-75 y 83-136.

Muller, Priscilla, Jewels in Spain 1500-1800, The Hispanic Society of America, New York, 1972.

Ortega Lamadrid, Paulino, «El emblema heráldico de las flechas de la Reina Isabel la Católica comentado por un humanista italiano», en Publicaciones del Instituto «Tello Telles de Meneses», n 6, 1951, pp. 111-115.

Philips, Clare, Jewels \& Jewellery, V\&A, London, 2 ed., 2008.

Pommier, Édouard, Théories du Portrait - de la Renaissance aux Lumières, Gallimard, Paris, 1998.

Pulgar, Hernando del, Crónica de los Señores Reyes Católicos Don Fernando y Doña Isabel de Castilla y de Aragón, Ed. Benito Monfort, Valencia, 1780.

Réau, Louis, Iconografía del arte Cristiano, tomo 2, vol. 4, Ed. del Serbal, Barcelona, 1997 [1957].

Redondo Cantera, María José, «Linajes, afectos y majestad en la construcción de la imagen de la emperatriz Isabel de Portugal», en Actas del Congreso Internacional de Imagen y Apariencia, Universidad de Murcia, 2008, pp. 1-17. [disponible en http://congresos.um.es].

Río de la Hoz, Isabel del, El Escultor Felipe Bigarny (h. 1470-1542), Junta de Castilla y León, Consejería de Educación y Cultura, 2001.

Roblot-Delondre, Louise, Portraits d'Infantes, Lib. Nationale d'Art et d'Histoire, Paris, 1913.

Ruiz Gómez, Leticia, «La creación del retrato español en el siglo XVI», en Ruiz Gómez, Leticia (ed.), El Retrato Español en el Prado, cat. Exp., Museo del Prado, Madrid, 2006, pp. 37-81.

Sánchez Cantón, Francisco Javier, Libros, tapices y cuadros que coleccionó Isabel la Católica, Instituto Diego Velásquez, Madrid, 1950.

Silva Maroto, Pilar, «La colección de pinturas de Isabel la Católica», en Checa Cremades, Fernando (coord.), Isabel la Católica - La Magnificencia de un Reinado, cat. Exp., Sociedad Estatal de Conmemoraciones Culturales / Junta de Castilla y León, 2005, pp. 115-126.

Smolderen, Luc, «Médaillons des Rois Catholiques Ferdinand et Isabelle», Revue Belge de Numismatique et de Sigillographie, Bruxelas, ano CXIV, 1968, pp. 81-93.

Trizna, Jazeps, Les Primitifs flamands, Contributions: Michel Sittow, peintre revalais de l'école brugeoise (1468-1525/26), Centre national de recherches «Primitifs flamands», Brussels, 1976.

Verougstraete, Hélène y Van Schoute, Roger, «La réalisation matérielle du tableau», en Patoul, Brigitte y Van Schoute, Roger, Les Primitifs Flamands et leur temps, La Renaissance du Livre, Tournai, 1998, pp. 101-115.

Vos, Dirk, Hans Memling - The Complete Works, London, Thames \& Hudson, 1994.

Wolff, Martha, «Michel Sittow», en Grove Art Dictionary Online, (artículo actualizado en 2010) Oxford Art Online, 15 Oct. 2011 URL: http://www.oxfordartonline.com/subscriber/article/grove/art/T079041.

Woodall, Joanna, Anthonis Mor: Art and authority, Waanders Publ., Amsterdam, 2007.

Yarza Luaces, Joaquín, Los Reyes Católicos. Paisaje artístico de una monarquía, Nerea, Madrid 1993.

Zalama, Miguel Ángel, «Juana I de Castilla: el inventario de los bienes artísticos de la Reina», in Checa Cremades, Fernando (dir.), Los Inventarios de Carlos $V$ y la familia imperial, vol. I, Fernando Villaverde Ed., The Getty Foundation, 2010, pp. 837-873.

Fecha de recepción: 21-XI-2011

Fecha de aceptación: 10-I-2012 